\title{
Erratum to: Intra-procedural determination of viability by myocardial deformation imaging: a randomized prospective study in the cardiac catheter laboratory
}

\author{
Alexander Schuh ${ }^{1} \cdot$ Vadim Karayusuf $^{1} \cdot$ Ertunc Altiok $^{1} \cdot$ Sandra Hamada $^{1}$. \\ Jörg Schröder ${ }^{1} \cdot$ Andras Keszei $^{2} \cdot$ Malte Kelm $^{3}$ - Matias de la Fuente ${ }^{4}$. \\ Michael Frick $^{1} \cdot$ Klaus Radermacher $^{4} \cdot$ Nikolaus Marx $^{1} \cdot$ Michael Becker $^{1}$
}

Published online: 2 June 2017

(C) Springer-Verlag Berlin Heidelberg 2017

\section{Erratum to: Clin Res Cardiol \\ DOI 10.1007/s00392-017-1099-9}

Unfortunately, an incorrect description of the contributions was provided in the Acknowledgements section. The correct Acknowledgements read as follows:

MB designed the study and managed research process, $\mathrm{MB}, \mathrm{AS}$ and VK chaired data acquisition and analysis and interpretation of results, VK wrote the report. MB, AS and VK had full access to all of the data in the study and took responsibility for the integrity of the data and the accuracy of the data analysis. Data were analyzed by $\mathrm{SH}$ and JS (DSE) and EA (CMR). MDF developed the medical-technical approach of image fusion. AK contributed to statistical interpretation of results. MK and NM contributed to data analysis and interpretation and reviewed the report. $\mathrm{MB}, \mathrm{NM}$ and $\mathrm{SH}$ contributed to the writing of the report.

The online version of the original article can be found under doi:10.1007/s00392-017-1099-9.

Michael Becker

mibecker@ukaachen.de

1 Department of Cardiology, RWTH Aachen University, Aachen, Germany

2 Department of Medical Statistics, RWTH Aachen University, Aachen, Germany

3 Department of Cardiology, University Hospital Düsseldorf, Düsseldorf, Germany

4 Medical Engineering, Helmholtz Institute for Biomedical Engineering, Aachen, Germany 